
T4D-6

\title{
SpelLit: Development of a Multi-Touch Application to Foster Literacy Skills at Elementary Schools
}

\author{
Florian Scharf, Silke Günther, Thomas Winkler, Michael Herczeg \\ Institute for Multimedia and Interactive Systems (IMIS), University of Luebeck \\ scharf|guenther|winkler|herczeg@imis.uni-luebeck.de
}

\begin{abstract}
This paper describes SpelLit, an application, which fosters literacy skills at elementary schools. For the development of our educational software, traditional concepts of learning have been adapted to fit the UniTable, a multi-touch tabletop system for educational purposes, aiming at students of all ages. Multi-touch technology lets users interact in easy and direct ways with computers. Being able to combine auditory, visual and haptic senses can improve the quality of learning, especially for young children. In this paper, it is shown that aspects of learning improve when well-established learning concepts are mapped to this new kind of interface. The UniTable as well as SpelLit have been developed in a user-centered process during several iterations, tests, and discussions with children and teachers as well as a speech therapist. With their help, it was possible to design hard- and software, appropriate for the use in schools.
\end{abstract}

Index Terms - collaborative learning, literacy, multi-touch applications, tabletop computing

\section{INTRODUCTION}

Nowadays, teaching is altering from instructional methods to more student-centered education, partly based on constructivism. Children are given the possibility to actively participate in the educational process by using their motivation and creativity in order to deepen their knowledge in a field of own interest. They work in an explorative way and by that get an insight into many facets of education. There are high expectations towards teachers to base their lessons on new, liberal concepts. Thus, the way of teaching, learning, and also the educational materials are changing, in order to give children the right input and provide an interior differentiation within the teaching process. Computers are often considered for help, to create new learning scenarios and to support the teachers. Ideally, they shall decrease the amount of work and time for preparation, as the educational concepts are already worked out and implemented in the respective software. While new media finds its way into classrooms this does not imply that the basics of traditional educational concepts have to change drastically, but they have to be seen within a new context and mapped to the new possibilities of today's media. Therefore, we investigated new suitable forms of human-computer interaction and considered not only single well-proven educational approaches but tried to extract and combine facets of different approaches in order to get best results. Technology-supported materials offer some advantages compared to traditional methods if they are based on sound pedagogical concepts and properly integrated into lessons. With software-based materials, children can usually define the desired degree of difficulty and amount to learn selfdirectedly. This provides more freedom and personal responsibility and lets children regain their equilibrium before advancing to the next educational level [1]. Differentiation and individual help can be offered, as adaptive software can adjust to the needs of the children without further effort. Logic, integrated into new media can act in the background and give feedback without providing the feeling of being controlled or supervised. This way, teachers are able to observe everything from a greater distance and let children act self-dependently. It can also often be seen that many children who get in contact with new, interesting technology get highly motivated. Their motivation derives from curiosity to adapt new experiences to their existing world [2] and the playful element that is accompanied when using new media. Play is a key element of today's society [3] and encourages children to learn because of intrinsic drive. It motivates children to adapt new experiences to their existing world. This sounds very promising, but day-to-day teaching in schools concerning the integration of new media is sometimes different from the scenario explained above. Technology seems to be a burden for some teachers instead of giving them substantial support. During our cooperation with about 20 schools in the last 10 years, we could notice that several teachers seemed to have difficulties to cope with their use and maintenance. Also children had problems in getting techsavvy instead of being motivated as well as fascinated by technology and showing an eagerness to use and explore it within learning processes.

We investigated how to build a multimedia platform for learning purposes that every child is able to use with ease and came to the conclusion that a system, based on a multi-touch table comes closest to the designated aim. While observing children at work in school, it can often be seen that they gather around tables in groups of four or more and work together on the same topic. This way, all of the children can contribute to the given task and none of them has to be left out. Learning in groups and helping each other fosters teamwork and is a very important aspect, as one of 
the fundamentals of human beings is the interconnection and collaborative learning with one another [4]. Multi-touch tables create an environment that supports collaboration [5] unlike a conventional computer with only one child sitting in front, because these tables are more seamlessly integrated in the environment and seem to reduce the barrier between users and technology. When computers vanish into the background, people start to get aware of other people in their environment and the centripetal forces that have been brought into the schools by computers can be reverted [6].

Multi-touch provides an almost natural and direct interaction, which may be not as precise as a mouse but is easier to handle for children. It improves multimodal learning by addressing multiple senses, because additionally to hearing and seeing, it is possible for children to "touch" everything they see and by this interact with objects on their desktop. Children have different ways of learning. Some set the focus to learning with their hands, some learn by listening or repeating, some by watching or by a combination of multiple senses. If many senses get involved during a process of learning, there is a higher chance of reaching the right sense for every child and thus the probability that children really understand the topic at hand increases [7]-[8].

\section{RELATED WORK}

Multi-touch devices become more popular within the educational sector as companies believe in the potential of their easy to use interface. But the ideas for appropriate educational software are still at an early stage. The obvious problem is the lack of pedagogical methods fitting well enough to the technology. So we related our technological concepts to well understood and practiced pedagogical concepts. As the main focus of this paper lies on the SpelLit software, we would like to give only a short example of an educational multi-touch based system from SMART Technologies.

SMART Technologies has been familiar with the educational sector for many years [9]. They developed a multi-touch table for the use in schools. The software and height of the table implies that it is designed for elementary schools as it is very low and offers mostly basic matching exercises in order to train mathematics and literacy skills. New software is in development and according to SMART, it is also possible to either use the toolkit in order to modify existent games with own content or develop and install own software. Like the SMART table, our UniTable System is also very low in height, but can be adjusted to suit the body height of children.

\section{Jürgen Reichen}

Jürgen Reichen was a teacher and progressive educator. During his work as a teacher, he developed a concept known as reading by writing [10]. He says that the emphasis lies on the importance of learning how to write, because those who can write will automatically be able to read some day. Writing is said to be the primary foundation of reading.
Children can learn how to read out written text, but they often cannot link words and their meanings. According to Reichen, this problem can be avoided when children learn to write at first.

His concept to facilitate the process of learning to write uses a phonics-letter-chart which only shows initial sounds with corresponding example images. These sounds make up the German phoneme inventory and help children to create a link between written and spoken words as children are able to split spoken words into their phonemes and to write them down. Phonemes can be found in every language. There are differences between the relation of the pronunciation of words and their spelling, e.g. German phonemes are bound to the spelling more closely than English, but the principal underlying the game can be mapped to a vast variety of languages with only slight changes. Even if a child does not know the complete alphabet, with this method, it is still able to write down the words by looking at the corresponding pictures and copying the letters for each initial sound. This way the phonological awareness of children is trained and they learn how to write spoken language in a playful way. As a side effect they start reading by speaking out each of the single phonemes as well as the completed words.

The phonics-letter-chart is considered very controversial [11] as it is not suitable for children with an inaccurate articulation. These children always need the guidance of a teacher, otherwise they do not get appropriate feedback or help. Teachers can support by helping to read out the initial sounds or observing and correcting the children and by giving assistance when needed. In order to use the chart efficiently, children must be able to work on their own. Those who easily lose concentration or must be constantly motivated are not able to learn reading and writing according to Reichen's method. Also collaboration of students using the phonics-letter-chart does not come automatically. It is often seen that children are deterring each other when they share only one chart and when each child has its own chart, they mostly work for themselves or ask the teacher for help. There are several software approaches like $\mathrm{T}^{3}$ [12] that try to avoid these disadvantages.

\section{TECHNICAL BACKGROUND}

The multi-touch technology was pursued for several reasons. The new educational environment, which is different from conventional computers, opens up new design possibilities, which have great influence on the usability and the efficiency of work processes. There can be direct interaction with hands on the table-like screen and also objects can be used that are identified via small markers, so-called fiducials [13]. The combination of virtual reality with tangible media permits an interconnection of both worlds, which feels quite natural to most children as they master their sensory-motor skills quite well from early childhood on [14]. Using physical objects facilitates "grasping" of computers and eliminates another barrier 
resulting from the difficult usage of conventional computers, with children as well as teachers.

The seamless integration of multimedia helps to present and embody realistic images of the user's notions, which he can grasp and manipulate. Sound, physics and 3D engines make it possible to show almost perfect virtual representations of real life physical objects in appearance and behavior. They can help to perform and simulate realistic, complicated or expensive experiments at no risk and with little effort.

The UniTable multi-touch system is based on the Diffused Surface Illumination approach (DSI). The setup is similar to the Frustrated Total internal Reflection (FTIR) setup [15], which provides good blob recognition in bright ambient light conditions, but due to a special acrylic plate, also has the advantage of recognizing fiducials. Thus it is possible to use finger tracking as well as tangible media as an input method.

The basic function of a DSI setup is quite easy to explain, although the realization of a working system is a rather delicate matter. Infrared LEDs beam into the sides of a special Enlightment ${ }^{\mathrm{TM}}$ acrylic plate. Because of small particles inside the plate, not all of the infrared light gets reflected inside the acrylic like it does within a FTIR setup. Some gets through the acrylic to the upper side and downside and thus can illuminate objects lying on top in addition to fingers swiping over the screen. The emitted infrared light is picked up by a camera, which is equipped with a visible-light filter and sensitive at wavelengths above $800 \mathrm{~nm}$. These signals are processed by a tracking software e.g. Community Core Vision [16] in order to get the relative Cartesian coordinates of each blob or fiducial that are sent to an application as multi-touch events.

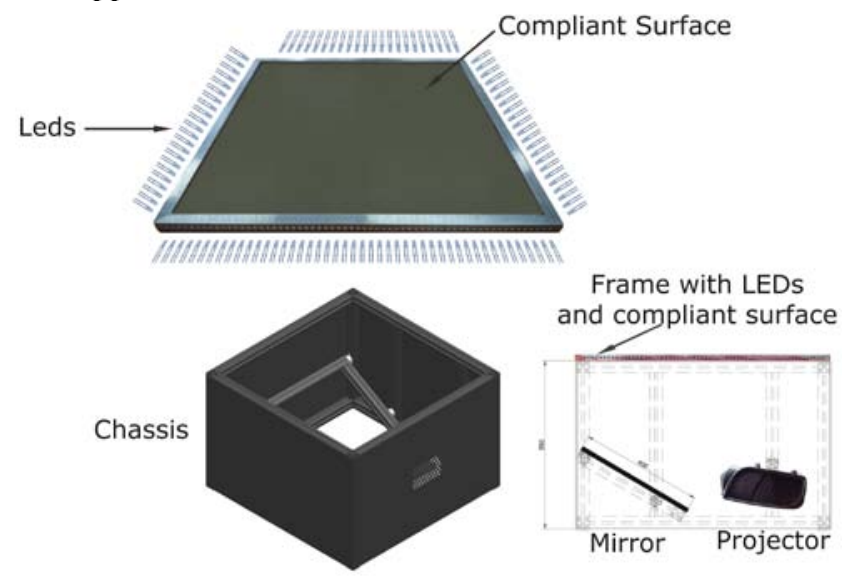

FIGURE I

THE UNITABLE SETUP

Besides the standard technical aspects of a multi-touch system, embedding it within an educational context demands for other requirements to be met by the UniTable system. It is best to build such educational systems in an iterative, user-centered process in cooperation with children in order to minimize the number of possible mistakes that can be made [17]-[19]. For convenient use, the table has to be very low, so that even small children can use it with ease and must not be too large that everything is within reach. Regarding the constant motor activity of younger children and the possibility of a more active interaction, it was decided together with a teacher not to let the children sit around the table primarily but let them stand around it.

\section{SPELLIT}

We investigated ways of helping children to read and write more efficiently and started by examining traditional concepts and considering the phonics-letter-chart of Reichen. Since the chart is already available in form of software for PCs, we did not just transfer it to a PC but combined it with another educational approach and adapted it to the new capabilities that multi-touch tables offer.

The concept of Reichen has similarities to the Freinet printing press [20]. They both encourage children to learn in an independent way and to create words or even sentences on their own. In contrast to Reichen, Freinet offers more active educational elements like the grasping of letter stamps for his printing press and the process of actual printing, which plays an important role in the educational development for small children. We wanted to transfer both ideas to the multi-touch table in order to try a new approach to teaching literacy and give children, regardless of their social background, the same chance. By combining visual with haptic and auditory elements the greatest possible effect in multisensory learning can be achieved. Grasping letters and playing with them fosters a mental connection between the virtual representation and the written word. But also auditory feedback in form of properly spoken words is essential for children with inaccurate articulation as their success on reading by writing depends on it. Another important aspect is motivation, especially with children who get easily distracted. It could be seen in our exhibitions and different observations of the UniTable that multi-touch tables fascinate children. Thus, these tables can help to increase the motivation to learn and by that foster a cognitively longer lasting learning experience [20].

In order to discuss the game idea and to know what is furthermore regarded as important concerning educational aspects, we involved a speech therapist. It was found out that the demands for the software varies very much depending on the level of education and especially if the child has any difficulties, for instance ADHD. In general, it can be said that it is best to keep the concept and layout very simple. Children get easily distracted by all kinds of things and lose focus on their actual tasks. Thus it is recommended to reduce the design to the minimum of needed elements.

SpelLit has been designed for four players but can be played with up to six, if desired. It is not specified whether the children play by themselves or in groups of two or three. It is up to them how they want to play, as every way has its advantages and challenges. It is neither a competitive game nor a time based one. This way of game-play was chosen on purpose as the difficulty of words and the level of knowledge of the children differ very much. Children also 
need their time to listen to and grasp the initial sounds and think about a solution.

For preparations, teachers can choose pictures from the Internet, appropriate for their didactic aims and put them into the matching folders of the operating system. There is one drawback, though. As it is very complicated to split the names of the pictures according to their initial sounds because of several rules, it was not possible to find an easy way to automate this process. Thus, in the current version, teachers have to name the pictures with an underline character between the initial sounds in advance, e.g. AU_T_O.jpg, for further computer processing. The game idea is kept very simple and is split into two stages.

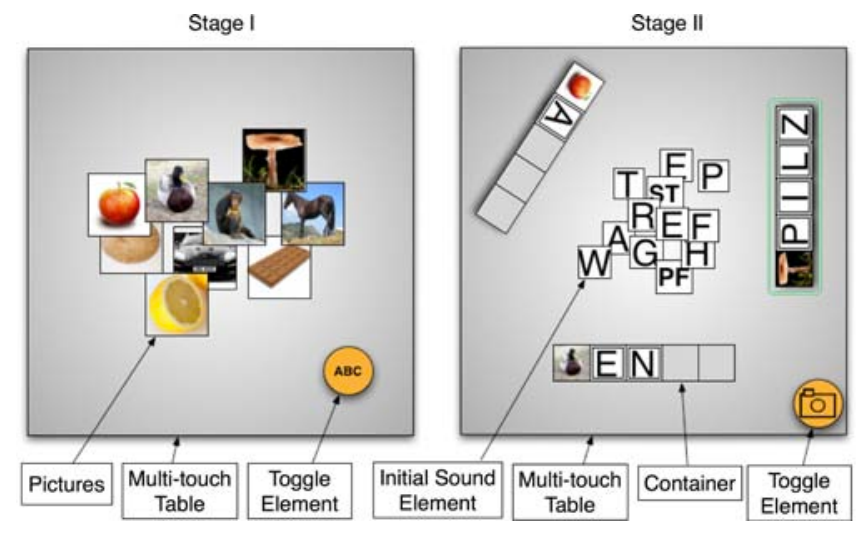

FIGURE II

THE TWO STAGES OF THE SPELLIT GAME

At the first stage, ten pictures are randomly taken out of the folder and presented on the screen. The children can move the pictures and rotate them in any way desired in order to take a closer look and choose whether they want to work with them. When a child chooses a picture it wants to spell the name of, the picture has to be pressed for about three seconds with three fingers in order to be activated. Then the picture gets highlighted, so that it can be seen that the status has changed to "activated". Although this procedure seems to be a bit complicated, it is easy to understand and a good way to distinguish between normal gestures and an intended activation. The built-in time delay reduces the possibility of false activation to a minimum. In case of an unwanted activation the action can always be undone.
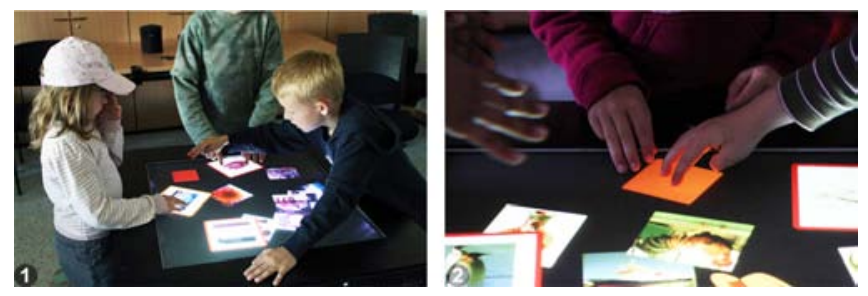

FIGURE III

CHOOSING PICTURES AND USING THE TOGGLE ELEMENT

When the children inform each other that everyone has picked and activated the desired picture and is ready to start, they can move on to the second stage. This is done by pressing a floating element that is used as a toggle element between the initial sounds- and the pictures-view for three seconds with three fingers. All non-activated pictures disappear and the initial sounds come up in the middle of the screen. As the pictures are not needed anymore they would just lead to confusion of the children and also block space that is necessary for the initial sound elements and a better workflow. It was chosen to present all elements that are needed for the solution at once, plus ten randomly chosen elements from a list of sound elements that do not appear in any of the words in order to increase the difficulty. The residing activated pictures are now placed within a grid, which is supposed to hold the initial sound elements. The grid is subdivided into a number of containers, each of which is able to carry exactly one initial sound element.

The children are supposed to write the word of the presented picture with the help of the initial sounds. It is up to them whether they want to solve this task alone or with the help of others. They can grasp letters from the middle of the table, move or turn them around or pass them on to someone else. By pressing one of the letters for a very short time, the initial sound gets read out. By this, the children can build a mental association between letter, sound and picture. When the containers of a picture are completely filled with initial sound elements, the correctness of the written word is verified automatically and the state is shown in form of a green or red rectangle around the word. Then, the word can be corrected if needed.

Reichen says that children often make mistakes during the first half of a year of using the phonics-letter-chart that derive from writing by hearing, e.g. they write "Aisberg" instead of "Eisberg" because "Ai" and "Ei" sound the same. He claims that it is best not to correct them for some time, as they can get confused otherwise. We worked together with children in the 1st grade, who are not new to literacy as they were at the end of term. Thus the developed literacy software is very strict and only accepts correctly spelled words, but this behavior does not interfere with the proposal of Reichen.

\section{EVALUATION}

The evaluation of the educational game was carried out with children from the "KITA Kleine Klosterkoppel", a day care center that takes care of children between 3 and 6 years of age. In addition to the day care center, the game was played with mentally and physically disabled children from the incorporated society "mixed pickles", but not as intensively evaluated as with the other children. There were great differences concerning the cognitive and sensory-motor skills of the disabled children. Some of them had problems to figure out how to play the game and spell words but they were supported very much by the others and were highly motivated.

The evaluation with the day care center group was done based upon the Solomon-4-group-model [21]. This implied that we worked with two groups, which were testing 
different settings and then switched places. The first group played the literacy game with the UniTable system, whereas the second group used the pen and paper method with the help of the phonics-letter-chart of Reichen. The groups were not biased until they switched places, as they both got in contact with the setup for the first time.

There were two video cameras installed in each setup that filmed the scenarios for further analysis. It was possible to observe how children behaved and handled tasks in each setup without prior experience and after that, it could be further observed in how far the use of one of the setups influences the handling of the other.

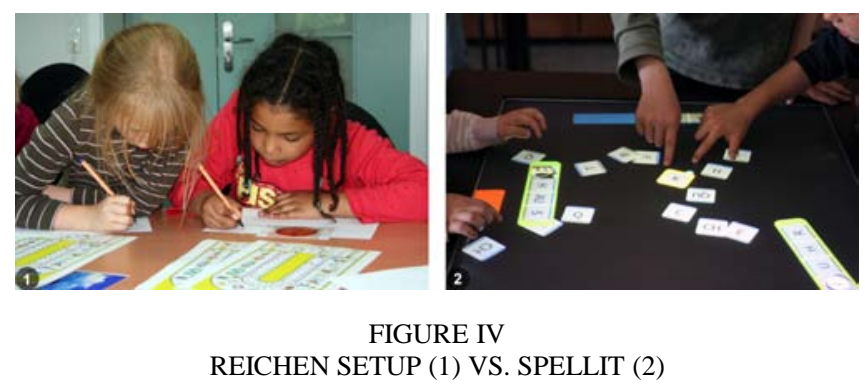

Pen \& Paper Reichen Setup

After a short introduction of the tasks to be performed, the children of the pen and paper group were each given a pile of photos from which they could choose whichever they wanted. Choosing pictures took quite long as they surveyed the whole pile prior to picking the photo of the word they wanted to spell. The further interaction was very different, depending on the cognitive state of the children. Fast learners did not need much help and fulfilled the given tasks on their own and it was seen that they did not use the phonics-letter-chart very often. They just thought about the words and wrote them down, letter by letter and if they had problems, they sometimes spoke the words out aloud. They were mostly able to solve problems by themselves but sometimes had to ask the supervisor for help. However, the slow learners had many problems with the concept of Reichen. They tried to stick to the letter-chart, but had problems with using it correctly and had to be individually supported in order to achieve their goals. It could be observed that they split words into their initial sounds but were sometimes irritated by the pictures of the letter-chart and asked the supervisor many questions, but they did not ask the other children for help. The supervisor also had to read out the initial sounds in order to give these children a hint. Thus, there was no evidence of improvement to be found that Reichen's method fosters collaboration. Although more liberal than former educational concepts, it is still close to the ex-cathedra teaching with children sitting at their tables and teachers imparting knowledge to them.

\section{UniTable Setup with SpelLit}

The SpelLit game of the UniTable was used like a puzzle, where the children helped one another and were collectively looking for the needed element in order to fulfill their tasks.
Searching for the right letters was fun, whereas in the Reichen setup the children mostly made no attempts to look up the initial sounds. It could be seen that the children at the UniTable sometimes called for help, but they did not ask the supervisor. Instead, their questions were directed to the others standing at the table, who were willing to help and integrated them into the learning process. Thus, there was no need for the supervising person. The help was sometimes given instantly and sometimes later when the others had finished their own work. The children offered their help in different ways. If a special letter was needed, they searched for it and it was passed over. If a child did not know what the next letter of the word could be, the others proposed the next initial sound element and passed it over or completed this step for the other one. Sometimes children only accepted the initial help and then said that they wanted to complete the task by themselves.
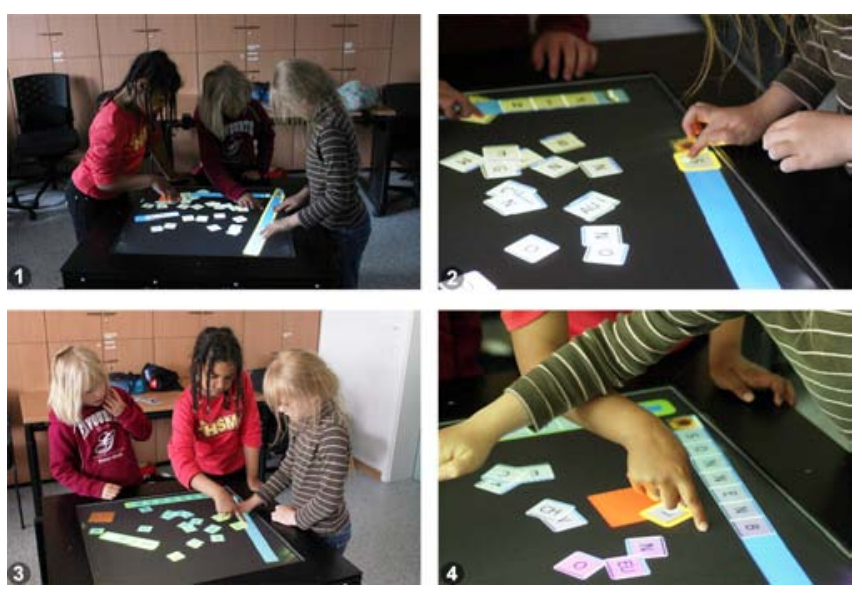

FIGURE V

1-2 CHILDREN SPELLING WORDS 3-4 CHILDREN HELPING EACH OTHER

It could also be noticed that they discussed letters when they had different opinions or were unsure. For example, one group had problems with the word "Hund". All three children of that group were not sure whether it is written with a "d" or " $\mathrm{t}$ ". The next step was to tap on it and listen to the initial sound. As they did not get a sufficient result and as the ending of the word is hard to guess by listening, they completed the word together, filled in the "t" and watched its frame. When it was not turning green, they knew that " $\mathrm{t}$ " was the wrong letter and changed it. There were also similar problems, which could not be solved with the help of the SpelLit game because of the children's own articulation. They were not able to guess where they made a mistake because they felt confident about their own pronunciation.

The chronological order of the used setups did not seem to influence slow- as well as fast learners very much. The fast learners had no problems with neither of the setups. They seemed to work more efficiently on their own with the pen and paper setup as they constructed more words during the same time. This may result from the fact that they helped other children and also that they had to wait for the 
others because of the two stage scenario. The slow learners on the other hand had problems with both scenarios, but seemed to be highly motivated using SpelLit. They seemed to have fun working and did not want to quit. This leads to the hypothesis that the SpelLit game has positive impact on learning, but it has to be evaluated over a much longer period of time.

\section{CONCLUSION AND FURTHER WORKS}

The evaluation demonstrates that multi-touch tables can enhance education with the help of appropriate software. The SpelLit software in combination with the UniTable contributes to the motivation to learn, as the interaction is easily graspable and much fun for children. It also fosters collaboration, which results in children learning from children without the need of a supervisor to interact frequently. This fact is not to be underestimated as it was clearly noticed that the pedagogue with the Reichen setup had to support the children a lot, whereas the supervisor of SpelLit mostly stayed in the background. It would be interesting to see if this motivation changes when the SpelLit game is integrated into day-to-day teaching and used on regularly basis. Unlike with traditional media, there is no chance of learning a wrong notation of words, because the Scrabble-like spelling of SpelLit always shows a correct notation.

A further improvement of the game is supposed to combine multi-touch abilities for displaying, choosing and handling pictures with tangible objects that can be explored and manipulated physically. According to Freinet and Montessori [20],[22], it is important for children to explore the world with their hands in order to grasp its content. This can be achieved if the tactile component of the multi-touch game is raised to the next level by using physical objects like a bar instead of a virtual grid, where children can put their fiducial-based, non-virtual, graspable letters.

As the Reichen letter-chart is not restricted to the German language and also used in other countries, this fact applies to the SpelLit game as well. This implies that UniTables of different countries could be connected and integrated into the NEMO network [23], a client server system that holds enriched multimedia objects. With these objects it is possible to store and exchange all relevant information and media content for the game among multiple devices, in this case UniTables. Thus, children of different countries could build their own word repository and exchange it among one another in order to get acquainted with other languages and cultures from early childhood, when it is still easy to learn foreign languages.

\section{REFERENCES}

[1] Piaget, J., “Development and learning.”, In: R. E. Ripple \& V. N. Rockcastle (ed..). Piaget Rediscovered , 1964, pp. 7-20.

[2] Bhattacharya, K., Han, S. 2001. "Piaget and Cognitive Development." In M. Orey (ed.), Emerging Perspectives on Learning, Teaching, and Technology.

http://projects.coe.uga.edu/epltt/index.php?title=Piaget's Constructivi sm. Accessed: 22 March 2010.
[3] Huizinga, J. "Homo Ludens.", Beacon Press. 1971

[4] Vygotsky, L.S. "Interaction between Learning and Development." In Mind in Society, (Trans.M.Cole), 1978. Cambridge, MA: Harvard University Press, pp. 79-91.

[5] Khaled, R., Barr, P., Johnston, H., and Biddle, R.. "Let's clean up this mess: exploring multi-touch collaborative play." In Proceedings of the 27th international Conference Extended Abstracts on Human Factors in Computing Systems, Boston, 2009, pp. 4441-4446.

[6] Weiser, M., "The Computer for the 21st Century.”, Scientific American, 1999, 265(3), pp. 94-104.

[7] Vester, F., “Denken, lernen und vergessen.”, Stuttgart, 1975.

[8] Nooriafshar, M., "A Multi-Sense Approach to Information Reception and Knowledge Creation in Learning." In: Third Pan-Commonwealth Forum on Open Learning (PCF3), Dunedin, New Zealand, 2004.

[9] "SMART Table." 2010. Smarttech.com. http://www2.smarttech.com/st/en-US/Products/SMART+Table. Accessed: 22 March 2010.

[10] Reichen, J., "Lesen durch Schreiben (German teacher's guide to Reading through Writing).”, Heinvetter, Lehrmittel Verlag, 1991.

[11] Brinkmann, E., Brügelmann, H. 2008. "Freies Schreiben im Anfangsunterricht?"

http://www.grundschulverband.de/fileadmin/grundschulverband/Dow nload/Forschung/brue.bri.eb.06.freies-schreiben.GSVa.forschung.ANHANG.erg.081108.pdf. Accessed: 22 March 2010

[12] Tewissen, F., Lingnau, A., Hoppe, U., et al., "Collaborative Writing in a computer-integrated classroom for early learning.", In Proceedings of Euro-CSCL (eds P. Dillenbourg, A. Eurelings \& K. Hakkarainen), Lawrence Erlbaum Associates , NJ, 2001, pp. 593-600.

[13] Kaltenbrunner, M., Bencina, R., "reacTIVision: A Computer-Vision Framework for Table-Based Tangible Interaction.”, In Proceedings of the 1st international Conference on Tangible and Embedded interaction, TEI '07. ACM, New York, NY, 2007, 69-74.

[14] Piaget, J., "Das Erwachen der Intelligenz beim Kinde.", Stuttgart, 1975.

[15] Han, J.Y., "Low-Cost Multi-Touch Sensing through Frustrated Total Internal Reflection.”, In Proceedings of the 18th Annual ACM Symposium on User interface Software and Technology. UIST'05, ACM, New York, 2005.

[16] "Community Core Vision." 2010. Nuigroup.com. http://ccv.nuigroup.com. Accessed: 22 March 2010.

[17] Druin, A., “The Design of Children's technology.”, Morgan Kaufmann, 1999.

[18] Mayhew, D. J., “The Usability Engineering Lifecycle.”, Morgan Kaufmann, San Francisco, 1999.

[19] Markopoulos, P., Read, J., MacFarlane, S., Höysniemi, J., "Evaluating Children's Interactive Products.", Morgan Kaufmann, San Francisco, 2008.

[20] Temple, C., Haché de Yunén, A.M., Montenegro, L., "Reading around the World: The "Global Method" of Célestin Freinet: Whole Language in a European Setting?", The Reading Teacher,1994, Vol. 48, No. 1 , pp. 86-89.

[21] Gollwitz, M., Jäger, R., “Evaluation.”, Workbook: Weinheim, Basel, 2007.

[22] Montessori, M., "Die Entdeckung des Kindes." Freiburg, Herder, 1969.

[23] Feldner, B., Guenther, S., Schmitt, F., Winkler, T. and Herczeg, M., "A Dolphin is a Dolphin? Multimedia Enriched Learning Objects in NEMO.", Ninth IEEE International Conference on Advanced Learning Technologies (ICALT), Riga, 2009, pp. 29-31. 